\title{
COVID-19-induced acute kidney injury in critically ill patients: epidemiology, risk factors, and outcome
}

\author{
Ahlem Trifi ${ }^{1,2}$, Sami Abdellatif ${ }^{1,2}$, Yosri Masseoudi ${ }^{2,3}$, Asma Mehdi ${ }^{1,2}$, Oussama Benjima ${ }^{2,3}$, Eya Seghir ${ }^{1,2}$, Fatma Cherif ${ }^{2,3}$, \\ Yosr Touil $^{1,2}$, Bedis Jeribi ${ }^{2,3}$, Foued Daly ${ }^{1,2}$, Cyrine Abdennebi ${ }^{1,2}$, Adel Ammous ${ }^{2,3}$, Salah Ben Lakhal ${ }^{1,2}$ \\ ${ }^{1}$ Medical Intensive Care Unit, University Hospital Center La Rabta, Tunis; ${ }^{2}$ Faculty of Medicine, Université de Tunis El Manar, Tunis; ${ }^{3}$ Department of Anesthesia, \\ University Hospital Center La Rabta, Tunis, Tunisia
}

Background: The kidney represents a potential target for severe acute respiratory syndrome coronavirus-2 (SARS-CoV-2). Clinical data about acute kidney injury (AKI) during SARS-CoV-2 infection are lacking. We aimed to investigate the proportion, risk factors, and prognosis of AKI in critical patients affected with SARS-CoV-2.

Methods: A case/control study was conducted in two intensive care units of a tertiary teaching hospital.

Results: Among 109 patients, 75 were male (69\%) with median age at 64 years and $48(44 \%)$ developed AKI within 4 days (interquartile range [IOR], 1-9). Of them, $11(23 \%), 9(19 \%)$, and 28 $(58 \%)$ were classified as stage 1,2, and 3, respectively. AKI patients were older and presented more sepsis, acute respiratory distress syndrome, and rhabdomyolysis; higher initial urea and creatinine; more marked inflammatory syndrome and hematological disorders; and required more mechanical ventilation and vasopressors. An elevated D-dimers level (odds ratio [OR], 12.83; 95\% confidence interval $[\mathrm{Cl}], 1.9-85)$ was an independent factor of AKI. Sepsis was near to significance $(\mathrm{OR}, 5.22 ; 95 \% \mathrm{Cl}, 0.94-28 ; \mathrm{P}=0.058)$. AKI was independently related to mortality $(\mathrm{OR}, 6.8$; $95 \% \mathrm{Cl}, 1.49-105)$ and significantly reduced the survival (14.7 days; IQR, 12-17 vs. 19.9 days; $I Q R, 17-22.7 ; P=0.011)$ in $A K I$ and no AKI group respectively. Hypoxemia with the ratio of the arterial partial pressure of oxygen and the inspiratory concentration of oxygen $<70$, and vasopressors were identified as mortality factors.

Conclusions: AKI occurred in almost half the studied patients and significantly worsened their prognosis. A high D-dimers level and sepsis contributed significantly to its development.

Key Words: acute kidney injury; coronavirus disease 2019; mechanical ventilation; mortality

\section{INTRODUCTION}

Severe acute respiratory syndrome coronavirus-2 (SARS-CoV-2) affects multiple organ systems and imparts significant morbidity and mortality [1]. Approximately $5 \%$ to $14 \%$ of patients affected with SARS-CoV-2 will become critically ill [2-4]. While coronavirus disease 2019 (COVID-19) generally begins as a respiratory tract infection, it can damage any organ system. Thus, to improve outcomes, clinicians should search actively for multi-organ involvement to guide appropriate early management [5].

\section{Original Article}

Received: July 9, 2021

Revised: October 17, 2021

Accepted: October 19, 2021

Corresponding author

Ahlem Trifi

Medical Intensive Care Unit, University Hospital Center La Rabta, Rue Jabbari 1007 Tunis, Tunisia

Tel: +216-9869-2699

Fax: +216-7157-5321

E-mail: trifiahlem2@gmail.com

Copyright (C) 2021 The Korean Society of Critical Care Medicine

This is an Open Access article distributed under the terms of Creative Attributions Non-Commercial License (https:// creativecommons.org/li-censes/by-nc/4.0/) which permits unrestricted noncommercial use, distribution, and reproduction in any medium, provided the original work is properly cited. 
Among affected organs, the kidney is particularly susceptible to COVID-19. Indeed, SARS-CoV-2 has been shown to share the same functional receptor, angiotensin-converting enzyme 2 (ACE2), with a wide variety of organs (such as lung, heart, kidney) [6]. SARS-CoV-2 initiates its infection process by binding to functional receptors on the membrane of a host cell. Postmortem examination of COVID-19 patients revealed varying degrees of acute tubular necrosis, lymphocytic infiltration, and viral RNA, suggesting direct invasion of kidney tubules [7]. In addition to direct kidney damage by the virus, acute kidney injury (AKI) can occur through several proposed mechanisms including acute tubular necrosis induced by sepsis, hypoxia, hypoperfusion, rhabdomyolysis, nephrotoxic drugs, etc.

In critically ill patients, AKI is a common complication of COVID-19 infection, occurring in $23 \%$ to $43 \%$ of cases [8-10], and was correlated with poor clinical outcomes [11]. At present, information regarding the epidemiology and the clinical correlates, prognosis, and determinants of AKI in patients with COVID-19 remain scarce. In this study, we aimed to evaluate the frequency, risk factors, and outcomes of AKI in critically ill patients with confirmed COVID-19.

\section{MATERIALS AND METHODS}

\section{Design}

This was a retrospective comparative case/control study conducted between September 2020 and December 2020 in two intensive care units (ICUs) designated for critical COVID-19 cases of the tertiary teaching hospital of La Rabta (Tunis, Tunisia). Regarding the two participating units, one was an existing medical ICU of multivalent activity managed by medical intensivists, and the other was a novel unit created especially for the COVID-19 outbreak and managed by anesthetists. The hospitalization capacity was six beds in both units. The Ethics Committee of La Rabta University Hospital approved the study protocol and waived informed consent because of the retrospective and descriptive nature of the study. The principles outlined in the Declaration of Helsinki as revised in 2013 were followed in the study protocol.

\section{Patients}

The medical records of all adult patients (>18 years) with laboratory-confirmed COVID-19 who were admitted to the two ICUs during the study period were examined. The SARS-CoV-2 RNA was detected using reverse transcription-polymerase chain reaction for laboratory diagnosis of COVID-19. The

\section{KEY MESSAGES}

- Acute kidney injury (AKI) occurred in $44 \%$ of critically ill patients affected with coronavirus disease 2019 (COVID-19).

- A high level of D-dimers and less significance of sepsis were factors related with the development of AKI.

- AKI increased the death risk by 6 and reduced survival by an average of 5 days.

- Elevated D-dimers was the most related factor to COVID-19-induced AKI that should emphasis more the role of micro thrombi and considers further the curative anticoagulation and immunomodulatory treatments.

samples consisted of nasal swabs or endotracheal aspirate. Patients who met the criteria of critical COVID-19 as defined below were included. The case group included the critical COVID-19 patients who presented with AKI during their ICU stay, and the control group was the critical COVID-19 patients who maintained normal kidney function. Excluded patients were those who did not meet the critical COVID-19 criteria, those whose medical records data were missing, and those with early multi-organ failure (MOF) including AKI.

\section{Therapeutic Management}

Standard care was based on oxygen support (invasive or noninvasive) associated with the prone position, corticosteroids (dexamethasone $8 \mathrm{mg} /$ day), anticoagulation, and vitamin supplementation. In our unit, the usual anticoagulation protocol was based on unfractionated heparins and low molecular weight heparin; the dose depended on curative or preventive indication, creatinine clearance, and weight of the patient. For the preventive protocol and creatinine clearance $>30 \mathrm{ml} / \mathrm{min}$ : if body mass index $(\mathrm{BMI})<30 \mathrm{~kg} / \mathrm{m}^{2}$, enoxaparin $0.4 \mathrm{ml} /$ day; if BMI $\geq 30 \mathrm{~kg} / \mathrm{m}^{2}$, enoxaparin $0.4 \mathrm{ml} \times 2 /$ day; and if weight $>120 \mathrm{~kg}$, enoxaparin $0.6 \mathrm{ml} \times 2 /$ day. In cases of clearance $<30 \mathrm{ml} / \mathrm{min}$ : heparin sodium $200 \mathrm{IU} / \mathrm{kg} /$ day or calciparin $150 \mathrm{IU} / \mathrm{kg} /$ day was administered in two subcutaneous injections. In the presence of confirmed thrombosis (pulmonary embolism or phlebitis), the curative protocol was as follows (patient weight: dose of enoxaparin) 50-59 kg: $0.5 \mathrm{ml} \times 2 /$ day, 60-69 kg: $0.6 \mathrm{ml} \times 2 /$ day, 70-79 kg: $0.7 \mathrm{ml} \times 2 /$ day, 80-89 kg: 0.8 $\mathrm{ml} \times 2 /$ day, $90-99 \mathrm{~kg} 0.9 \mathrm{ml} \times 2 /$ day, and weight $\geq 100 \mathrm{~kg}: 1 \mathrm{ml}$ $\times 2$ /day. If creatinine clearance $<30 \mathrm{ml} / \mathrm{min}$, intravenous heparin $3-5 \mathrm{mg} / \mathrm{kg} /$ day is administered continuously via electric syringe pump over 24 hours. 


\section{Assessed Data}

For each patient, we recorded demographics, comorbidities, basic drugs received, clinical features, initial laboratory findings, initial computed tomography (CT) scan data, treatment (respiratory supports, use of medications, and renal replacement therapy (RRT), and clinical outcomes. The daily values of urea and creatinine were recorded. All data were entered into the computerized database for further statistical analysis.

\section{Definitions}

A patient affected by COVID-19 was considered critical and required ICU transfer in the presence of respiratory distress (respiratory rate $\geq 30$ times/min plus cyanosis) and the use of oxygen support to maintain oxygen saturation as measured by pulse oximetry $\left(\mathrm{SpO}_{2}\right)>92 \%$. The oxygen support could be noninvasive including noninvasive ventilation (NIV) and highflow nasal cannula (HFNC) or invasive with requirement of ventilator support (mechanical ventilation [MV]). Shock and MOF were also considered critical criteria. The oxygen support modality recorded was that used before AKI (either on ICU admission or during hospitalization before AKI).

Sepsis was defined according to the 3rd international consensus (Sepsis-3); i.e., presence of organ dysfunction (identified as an acute change in total Sequential Organ Failure Assessment [SOFA] score $\geq 2$ points), consequent to the infection [12]. To avoid bias, we did not consider sepsis that included AKI at the time of diagnosis. It was only when sepsis preceded AKI that it was analyzed as a risk factor.

The definition and severity staging of AKI were based on the Kidney Disease: Improving Global Outcomes (KDIGO) classification [13] as follows. Stage 1 involves increase in serum creatinine to $1.5-1.9$ times baseline odds ratio $(\mathrm{OR})>0.3 \mathrm{mg} /$ $\mathrm{dl}(>26.5 \mu \mathrm{mol} / \mathrm{L})$ and/or urine output $<0.5 \mathrm{ml} / \mathrm{kg} / \mathrm{hr}$ for $6-12$ hours. Stage 2 is increase in serum creatinine to 2.0-2.9 times baseline and/or urine output $<0.5 \mathrm{ml} / \mathrm{kg} / \mathrm{hr}$ for $>12$ hours. Stage 3 is defined by increase in serum creatinine to 3.0 times baseline, increase in serum creatinine to $>4.0 \mathrm{mg} / \mathrm{dl}(>353.6 \mu \mathrm{mol} /$ L), initiation of RRT, and/or urine output $<0.3 \mathrm{ml} / \mathrm{kg} / \mathrm{hr}$ for $>24$ hours, or anuria for $>12$ hours. For patients without available baseline serum creatinine (bSCr), we estimated bSCr using the modification of diet in renal disease equation: back-estimation formula: serum creatinine $=[75 / 186 \times($ age -0.203$) \times(0.742$ if female $) \times(1.21$ if black $)-0.887$ ] as suggested by KDIGO guidelines to estimate bSCr in the absence of prior renal disease $[14,15]$. In patients with suspected chronic kidney disease, the lowest creatinine measured in the first three days of hospitalization was considered bSCr.

The definition of AKI recovery was based on that of the Acute Disease Quality Initiative 16 workgroup [16]. Rhabdomyolysis was retained if the creatine phosphokinase rate was greater than five times the upper limit of normal. Nephrotoxic drugs are those toxic to the kidney. In our unit, the most prescribed were colistin, aminoglycosides, vancomycin, and iodine contrast agent.

\section{Study Outcomes}

We focused mainly on frequency of AKI and its risk factors. We also assessed outcomes of AKI, RRT requirement, and the impact of AKI on mortality in critical COVID-19 patients.

\section{Statistical Analysis}

Continuous variables were expressed as the median and interquartile range (IQR) and compared with a nonparametric Mann-Whitney test. Categorical variables were expressed as counts and percentages and compared using a chi-square test or Fisher's exact test as appropriate. The risk factors for AKI and those associated with 28-day mortality were screened with the univariate logistic regression model. The variables with a P-value of 0.2 or less were analyzed with multicollinearity tests to clear interferences and overlaps and were imported into a logistic regression analysis using the entered method. Survival analysis was processed by the Kaplan-Meier curves and compared by the Log-rank test. The significance threshold was set at a two-sided P-value less than 0.05. All statistical analyses were performed using IBM SPSS ver. 20 (IBM Corp., Armonk, NY, USA).

\section{RESULTS}

\section{Baseline Characteristics and Proportion of AKI}

In the included 109 patients, male gender was predominant (75/34; sex ratio, 2.2), and the median age was 64 years (IQR, 57-71 years). Five of the patients had chronic renal failure. During hospitalization, AKI occurred in 48 patients (44\%). Table 1 shows the evaluated parameters in all populations and, for each group, according to presence of AKI. Laboratory and CT scan findings in the table are those collected at ICU admission. The AKI patients were older and had more frequent hypertension, higher severity scores, and more predisposing conditions (such as sepsis, acute respiratory distress syndrome [ARDS], and rhabdomyolysis) and required more frequent MV and vasopressors. Notably, prior use of ACE in- 
Table 1. Assessed parameters in all patients according to presence of AKI

\begin{tabular}{|c|c|c|c|c|}
\hline Variable & Total population $(n=109)$ & AKI group $(n=48)$ & No AKI group ( $n=61)$ & P-value \\
\hline Age & $64(57-71)$ & $69(61-77)$ & $60(55-66)$ & $<0.001$ \\
\hline$>60 \mathrm{yr}$ & $67(61.5)$ & $37(77)$ & $30(49)$ & 0.003 \\
\hline Sex (male:female) & $75: 34$ & $33: 15$ & $42: 19$ & 0.999 \\
\hline BMI & $27(24-31)$ & $27.3(24.5-30.7)$ & $27(24-32.5)$ & 0.620 \\
\hline Obesity $\left(\mathrm{BMI}>30 \mathrm{~kg} / \mathrm{m}^{2}\right)$ & $32(29.5)$ & $11(23)$ & $21(34.5)$ & 0.182 \\
\hline \multicolumn{5}{|l|}{ Comorbidity } \\
\hline Hypertension & $56(51.5)$ & $30(62.5)$ & $26(42.6)$ & 0.054 \\
\hline Prior use of ACE inhibitor/A2RB & $27(25)$ & $16(33.5)$ & $11(18)$ & 0.071 \\
\hline Diabetes & $44(40)$ & $23(48)$ & $21(34.4)$ & 0.175 \\
\hline Chronic renal failure & $5(4.5)$ & $1(2)$ & $4(6.5)$ & 0.388 \\
\hline Chronic respiratory failure & $20(18.5)$ & $8(16.5)$ & $12(20)$ & 0.804 \\
\hline Cardiomyopathy & $18(16.5)$ & $9(19)$ & $9(15)$ & 0.613 \\
\hline Immunocompromised & $6(5.5)$ & $4(8.3)$ & $2(3.3)$ & 0.489 \\
\hline \multicolumn{5}{|l|}{ Severity score } \\
\hline APACHE ॥ & $10.5(7-16)$ & $13(10-18)$ & $9(6-11)$ & $<0.001$ \\
\hline SAPS $\|$ & $30(22-40)$ & $38(31-53)$ & $24(16-30.7)$ & $<0.001$ \\
\hline SOFA & $4(3-9)$ & $7(4-11)$ & $4(2-7.5)$ & 0.001 \\
\hline \multicolumn{5}{|l|}{ Initial laboratory finding } \\
\hline Baseline serum urea (g/L) & $0.57(0.39-1.05)$ & $1(0.71-1.3)$ & $0.45(0.36-0.56)$ & $<0.001$ \\
\hline Baseline creatinine (mg/L) & $9(7-14)$ & $12.5(9-18.4)$ & $8(7-10)$ & $<0.001$ \\
\hline Minimum P/F ratio & $66(48-93)$ & $60(46-78)$ & $73(55-126)$ & 0.110 \\
\hline WBC count $\left(\times 10^{9} / \mathrm{L}\right)$ & $12(8.5-17)$ & $17(7-21)$ & $10(4-15)$ & 0.033 \\
\hline Minimum lymphocyte $\left(\times 10^{3} / \mu l\right)$ & $520(312-720)$ & $510(320-760)$ & $550(302-715)$ & 0.819 \\
\hline Platelet $\left(\times 10^{9} / \mathrm{L}\right)$ & $141(48-238)$ & $134(33-266)$ & $145(58-229)$ & 0.772 \\
\hline CRP (mg/L) & $199(98-280)$ & $248(171-326)$ & $151(74-242)$ & 0.002 \\
\hline Prothrombin time (\%) & $60(45-80)$ & $56(41-69)$ & $75(52-86)$ & 0.001 \\
\hline Fibrinogen $(g / L)$ & $5.1(1.7-6.4)$ & $5.5(4.2-6.9)$ & $2.5(1.5-6.2)$ & 0.179 \\
\hline D-dimer ( $\mu \mathrm{g} / \mathrm{L})$ & $1,402(653-3,881)$ & 2,222 (813-5,109) & $905(598-1,757)$ & 0.002 \\
\hline Lactate (mmol/L) & $2.1(1.6-6)$ & $2.1(1.7-4)$ & $1.9(1.6-3.6)$ & 0.448 \\
\hline CT scan lesion extension at admission ${ }^{\mathrm{a}},>50 \%$ & $33 / 78$ (42) & $13 / 31(42)$ & $20 / 47(42.5)$ & 0.999 \\
\hline \multicolumn{5}{|l|}{ Predisposing condition } \\
\hline Sepsis & $49(45)$ & $35(73)$ & $14(23)$ & $<0.001$ \\
\hline ARDS & $81(74)$ & $38(81)$ & $43(70.5)$ & 0.953 \\
\hline $\mathrm{ACP}^{\mathrm{a}}$ & $10 / 66(15)$ & $8 / 29(27.5)$ & $2 / 37(5.4)$ & 0.017 \\
\hline Rhabdomyolysis & $21(19)$ & $14(29$ & $7(11.5)$ & 0.086 \\
\hline Vasopressor & $60(55)$ & $40(84)$ & $20(33)$ & $<0.001$ \\
\hline Nephrotoxic drug & $29(27)$ & $20(42.5)$ & $9(15)$ & 0.014 \\
\hline \multicolumn{5}{|l|}{ Respiratory support } \\
\hline Alternation HFNC/NIV & $61(56)$ & $18(37.5)$ & $43(70.5)$ & - \\
\hline MV & $48(44)$ & $30(62.5)$ & $18(29.5)$ & 0.001 \\
\hline
\end{tabular}

Values are presented as median (interquartile range) or number (\%).

AKI: acute kidney injury; BMI: body mass index; ACE: angiotensin-converting enzyme; A2RB: angiotensin II receptor blockers; APACHE: Acute Physiology and Chronic Health Evaluation; SAPS: Simplified Acute Physiology Score; SOFA: Sequential Organ Failure Assessment; P/F ratio: ratio of the arterial partial pressure of oxygen and the inspiratory concentration of oxygen; WBC: white blood cell; CRP: C-reactive protein; CT: computed tomography; ARDS: acute respiratory distress syndrome; ACP: acute cor pulmonale; HFNC: high-flow nasal cannula; NIV: noninvasive ventilation; MV: mechanical ventilation.

${ }^{a} \mathrm{CT}$ scan performed in 78 patients and echocardiography in 66 patients. 
hibitor or angiotensin II receptor blocker (A2RB) was observed more frequently in the AKI group with $\mathrm{P}$ close to significance. Several biological differences were found; both initial urea and creatinine were higher in the AKI group. Moreover, inflammatory and hematological disorders were found more often in the AKI patients.

\section{AKI Characteristics and Risk Factors}

Among 48 patients (44\%) who developed AKI during hospitalization, 11 (23\%), 9 (19\%), and 28 (58\%) were classified as KDIGO stage 1, 2, and 3, respectively. Eight patients (17\%) received RRT ( 5 in the stage 2 category and 3 in the stage 3 category). AKI occurred within a median of 4 days [1-9].

Age over 60 years, hypertension, prior use of ACE inhibitor/ $\mathrm{A} 2 \mathrm{RB}$, diabetes, the ratio of the arterial partial pressure of oxygen and the inspiratory concentration of oxygen $(\mathrm{P} / \mathrm{F}$ ratio) $<70$, C-reactive protein (CRP) $>200 \mathrm{mg} / \mathrm{L}$, fibrinogen $>5 \mathrm{~g} / \mathrm{L}$, D-dimers $>1400 \mu \mathrm{g} / \mathrm{L}$, sepsis, rhabdomyolysis, MV, vasopressors, and nephrotoxic drugs were the factors introduced in the multivariate analysis. Conditions and factors included in the analysis were only considered if they preceded AKI. In the results, elevated D-dimers was an independent factor significantly associated with AKI in critical COVID-19 patients, with OR, 12.83; 95\% CI, 1.9-85. Sepsis tended to be a related factor with OR near significance (OR, 5.22; 95\% CI, 0.94-28; $\mathrm{P}=0.058$ ). These findings are shown in Table 2.

\section{Outcomes}

Renal function improved in only three patients (6.25\%), who were classified as KDIGO stage 1 . Ventilation days and ICU stay were similar between the two groups (6 [3-8] vs. 4 [2-8], $\mathrm{P}=0.12$ and 7 [5-10] vs. 8 [4-15], $\mathrm{P}=0.59)$ in patients with AKI and those without, respectively. Of 109 patients, 65 showed deceased mortality within 28 days of ICU admission (ICU 28day mortality, 59; $6 \%$ ), which was significantly higher in AKI patients $(41 / 48$ [85\%] vs. $24 / 61[39.4 \%], \mathrm{P}<0.001)$. All patients classified as KDIGO 3 died (Table 3 ).

In non-survivor patients, AKI, hypoxemia, sepsis, vasopressors, and MV requirements were more frequent than in survivors. Contrary to common findings, there were fewer obese subjects among deceased patients (Table 3). In multivariate analysis, $\mathrm{AKI}$, severe hypoxemia $(\mathrm{P} / \mathrm{F}$ ratio $<70)$, and vasopressors were associated with mortality (Table 3 ).

\section{Survival Analysis}

When AKI occurred in critical COVID-19 patients, it decreased
Table 2. Factors associated with AKI in multivariate analysis

\begin{tabular}{lcc}
\hline Variable & Odds ratio & P-value \\
\hline Age $>60 \mathrm{yr}$ & 1.35 & 0.320 \\
Hypertension & 1.58 & 0.612 \\
Prior use of ACE inhibitor/A2RB & 1.25 & 0.124 \\
Diabetes & 1.55 & 0.402 \\
P/F ratio $<70$ & 2.54 & 0.154 \\
CRP $>200 \mathrm{mg} / \mathrm{L}$ & 2.21 & 0.140 \\
Fibrinogen $>5 \mathrm{~g} / \mathrm{L}$ & 3.03 & 0.115 \\
D-dimers $>1,400 \mu \mathrm{g} / \mathrm{L}$ & $12.83(1.9-85)^{\mathrm{a}}$ & 0.008 \\
Sepsis & $5.22(0.94-28)^{\mathrm{a}}$ & 0.058 \\
Rhabdomyolysis & 6.53 & 0.072 \\
MV & 4.30 & 0.124 \\
Vasopressor & 1.82 & 0.466 \\
Nephrotoxic drug & 4.26 & 0.080 \\
\hline AKL: acute kidney injury; ACE: angiotensin
\end{tabular}

AKI: acute kidney injury; ACE: angiotensin-Converting enzyme; $A 2 R B$ : angiotensin II receptor blockers; P/F ratio: the ratio of the arterial partial pressure of oxygen and the inspiratory concentration of oxygen; CRP: C-reactive protein; MV: mechanical ventilation.

${ }^{\mathrm{a}} 95 \%$ confidence interval.

the survival delay time by an average of 5 days (14.7 days; IQR, 12-17 vs. 19.9 days; IQR, 17-22.7; $\mathrm{P}=0.011$ ) in AKI group and no AKI group respectively, as shown in Figure 1.

\section{DISCUSSION}

We showed that, among 109 critical COVID-19 patients, 48 (44\%) developed AKI that was mostly classified as KDIGO 3. At baseline, multiple clinical and biological differences between the AKI group and no AKI group were observed. Concerning the association with AKI, elevated D-dimers was the most significant independent factor. Sepsis was related closely to AKI. Overall, the 28-day mortality was poor at $59.6 \%$ and was higher in AKI patients (85\%). This complication was related to mortality (OR, 6.8; 95\% CI, 1.49-105) and significantly reduced survival.

\section{Descriptive Epidemiology}

Compared to other reported figures, our proportion of patients with AKI was high at $44 \%$. Indeed, AKI occurred in $0.5 \%-15 \%$ of hospitalized patients affected with SARS-CoV-2 [17] and in up to $23 \%$ of COVID ICU patients [8,9]. Before emergence of COVID, Panitchote et al. [18] reported an incidence rate of $68.3 \%$ for AKI after onset of ARDS. In 2009 influenza A (H1N1) viral pneumonia, the incidence of AKI reached 51\% [19]. Another multicenter study showed that AKI occurred in $31.3 \%$ of 
Table 3. Impact of AKI and risk factors of mortality

\begin{tabular}{|c|c|c|c|c|}
\hline Variable & Survivor $(n=44)$ & Non-survivor $(n=65)$ & Multivariate analysis, OR (95\% Cl) & P-value \\
\hline AKI & $7(16)$ & $41(63)$ & $6.8(1.49-105)$ & $<0.001$ \\
\hline KDIGO 1 & $3(43)$ & $8(19.5)$ & & 0.322 \\
\hline KDIGO 2 & $4(57)$ & $5(12)$ & & 0.017 \\
\hline KDIGO 3 & 0 & $28(68.5)$ & & 0.001 \\
\hline Age (yr) & $60.5(56-70)$ & $66(58-72)$ & NS & 0.048 \\
\hline Obesity & $19(43)$ & $13(20)$ & NS & 0.007 \\
\hline SOFA score & $3(2-4)$ & $6(4-11)$ & NS & 0.035 \\
\hline Minimal P/F ratio & $93(65-166)$ & $59(45-74)$ & $20(1.73-236)$ & $<0.001$ \\
\hline Sepsis & $4(9)$ & $45(69)$ & NS & $<0.001$ \\
\hline Vasopressor & $4(9)$ & $56(86)$ & $15.29(1.23-189)$ & $<0.001$ \\
\hline MV & $5(11.3)$ & $43(66)$ & NS & $<0.001$ \\
\hline
\end{tabular}

Values are presented as number (\%) or median (interquartile range) unless otherwise indicated.

AKI: acute kidney injury; OR: odds ratio; Cl: confidence interval; KDIGO: Kidney Disease: Improving Global Outcomes; NS: not significant; SOFA: Sequential Organ Failure Assessment; P/F ratio: the ratio of the arterial partial pressure of oxygen and the inspiratory concentration of oxygen; MV: mechanical ventilation.

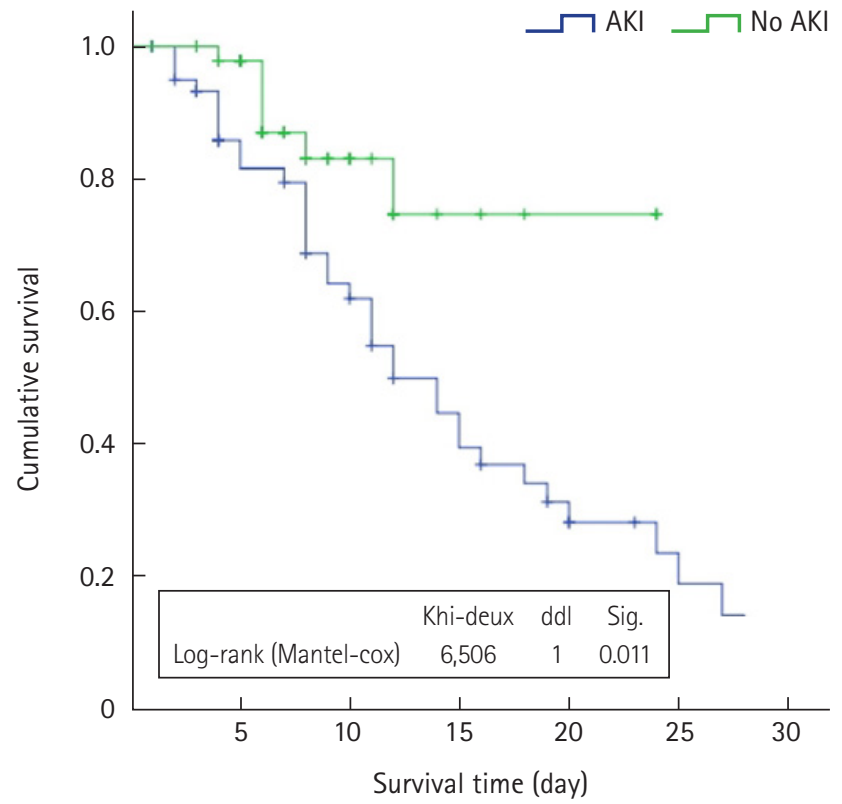

Figure 1. Survival analysis according to presence of acute kidney injury (AKI). ddl: degre de liberte; Sig: significance.

patients and was more common in patients with ARDS $(44.3 \%$ vs. 27.4\%, $\mathrm{P}<0.001)[20]$.

In patients with severe COVID-19, the progression to ARDS is almost constant, which partly can explain our elevated number of affected patients. All our patients were deeply hypoxic and required a high flow of oxygen either noninvasively (NIV or/and HFNC in 56\%) or invasively (MV in 44\%). This partly allows arguing this considerable proportion of AKI. In a Chinese series, the incidence was very close to ours at $43.8 \%$ [10]. In our distribution, AKI severity was similar to that in the Chinese study (for stage 3: 58\% and $69.6 \%$, respectively) [10]. The high proportion of stage 3 is explained by the serious profile of the patients studied. The median onset of AKI from hospitalization ranges from 7 [11] to 15 days [17], but our delay was shorter at 4 days [1-9]. Before the era of COVID, we conducted a correlation study and we found that the most significant correlation was detected at 48 hours from hypoxemia. This is supported by the present results in the era of COVID-19. Herein, major hypoxemia (judged by a threshold $\mathrm{P} / \mathrm{F}$ ratio $<70$ ) was not an independent factor of AKI (OR, 2.54; $\mathrm{P}=0.15)$. Factors other than hypoxemia highly negatively affect the kidney during SARS-CoV-2 invasion.

\section{Analytical Results}

We showed that a high level of D-dimers increased the risk of AKI by 13 times. This is an original result and has not been reported previously. What is known is that the significant inflammatory response to the virus causes damage to organs including the kidney. However, neither elevated CRP nor elevated fibrinogens were factors of renal injury (Table 2). D-dimers appear to be the most highly associated factor. Unfortunately, renal histological data were not available in our series to support this finding.

This strong relation suggests the important role of microthrombi in the genesis of AKI. Thrombo-embolic complications during COVID-19 infection have become common, but their extensive involvement in the pathogenesis of AKI is unclear. Based on current evidence, the injured sites and the cor- 
responding mechanisms in COVID-19-induced AKI are acute tubular necrosis (due to tubular lumen dilatation with cellular debris and changes in the brush border membranes of proximal tubules), acute interstitial nephritis (due to mononuclear cell infiltration within the interstitium), podocytopathy (due to podocyte foot process effacement, collapsing glomerulus pseudo crescent formation), and thrombotic microangiopathy (due to microthrombi within the glomeruli) [21]. Our results emphasize the significance of the 4th mechanism. A kidney biopsy revealed severe acute thrombotic microangiopathy with cortical necrosis [22]. This disorder cannot be included in the disseminated intravascular coagulation (DIC) entity. In our series, for example, two key diagnostic items of DIC were missing: fibrinogen was rather high (as often is in COVID-19 infection) and platelet count was normal. Clearly, the potential pathological kidney changes in patients with COVID-19 require further study.

Otherwise, we demonstrated that sepsis was close to being a significant factor of COVID-19-induced AKI (OR, 5.22; $\mathrm{P}=0.058)$. Sepsis is a condition predisposing the patient to AKI $[10,18,23]$, and AKI is a possible factor in the definition of sepsis according to the last Sepsis-3 consensus [12]. To remove the cause/effect confusion bias (COVID/AKI or sepsis/AKI), we considered sepsis only when it occurred before AKI. The pathogenic mechanisms of sepsis-induced AKI are different from those seen in other causes of AKI.

A review by Zarbock et al. [24] emphasizes the important role of inadequate responses to sepsis. The adaptive responses of tubular epithelial cells to injurious signals are responsible for renal dysfunction. Simultaneously, renal inflammation and microcirculatory dysfunction further amplify these mechanisms [24]. The cytokine storm and micro thrombotic disturbances triggered by SARS-CoV-2 predispose patients with sepsis to AKI compared to those who have not developed sepsis.

In addition to the indirect effects of the immune-inflammatory response to the virus, the direct effects of the viral infection should be considered. These effects largely reflect the ability of the virus to use the ACE2 receptors to gain entry into endothelial cells $[25,26]$. Since these receptors are widespread in the kidney, they are considered as a potential target for SARS-CoV-2. In our series, AKI did not occur less frequently in patients receiving test drugs, and multivariate analysis did not reveal any protective effect. However, this study was an indirect and not precise assessment of the effects of the virus on the kidney.

Other factors are presumed to be harmful to the kidney and their presence with severe affection caused by SARS-CoV-2 could contribute to the occurrence of AKI. From these factors, we were interested in old age, metabolic morbidities (diabetes and hypertension), MV, vasopressors, rhabdomyolysis, and nephrotoxic drugs. None of these factors were independently associated with AKI. This negative result can be explained by the small size of the studied sample and deserves to be reexamined in a larger population. Different from our findings, Sang et al. [10] showed that MV increased significantly the risk of AKI (OR, 9.72; 95\% CI, 2.93-32.24; $\mathrm{P}=0.0002)$. This relationship can be explained by the mechanisms of lung-kidney cross-talk [27,28], regardless of the cause of ARDS. Animal models suggest a causal relationship between MV and AKI via a reduction in renal blood flow due to a drop in cardiac output secondary to the changes in intrathoracic pressure; mainly caused by extrinsic positive end-expiratory pressure (PEEP) [29]. Some parameters used for the lung protective ventilation strategy (such as low tidal volume, limited plateau pressure, and suitable level of PEEP) were shown to be protective for AKI [28].

\section{Outcomes}

Both our results and other reports $[10,11]$ agree that the occurrence of AKI during COVID-19 worsened morbidity and mortality. Patients of the KDIGO 3 category died more often (OR, 5.33; 95\% CI, 1.15-24.65) in a Chinese study [10], and all the patients of our series in this category died. Given the very small number of survivors among the AKI patients (7/48), we did not perform a multivariate analysis to determine the mortality factors in the AKI group with COVID-19. Cheng et al. [11] revealed that patients with initial kidney abnormalities (elevated serum creatinine, proteinuria, hematuria, and AKI) have a significantly higher in-hospital death rate. Beyond AKI, severe hypoxemia with $\min \mathrm{P} / \mathrm{F}$ ratio $<150$ was independently related to mortality in the study by Sang et al. [10], which was in accordance with our results.

Despite their statistical significance and even if previous studies show supporting findings (i.e., mortality was associated with AKI, other organ failure, or use of vital assistance such as vasopressors or MV), these findings represent a source of confusion. More reasonably, they are consequences of deterioration rather than predictors of deterioration. As an example, many patients with sepsis eventually die with MOF syndrome, and the MOF usually includes AKI. In addition, the largest deterioration was observed in patients who required vital support from MV or vasopressors. Similarly, these factors are 
outcomes rather than factors of excess mortality in the present study.

On the other hand, we showed a result (more survivors in the obese subgroup; $43 \%$ vs. $20 \%, \mathrm{P}=0.007$ ) that we believe is inconsistent with the most commonly reported findings. Most probably, this was a coincidence without a real association.

We concluded that the proportion of AKI in critically ill patients with COVID-19 was considerable. High levels of D-dimers and, less significantly, sepsis were the most concerning factors. Once they occurred, the prognosis was significantly worse. Early detection and careful monitoring of renal function and D-dimers can help to reduce the deaths of patients with COVID-19. Our findings should place more emphasis on active anticoagulation and further investigation to detect an eventual acute thrombotic microangiopathy caused by SARSCoV-2.

\section{CONFLICT OF INTEREST}

No potential conflict of interest relevant to this article was reported.

\section{ACKNOWLEDGMENTS}

All the authors express their thanks to the English teacher Mr. Moez Ghrairi for his help in correcting the English of our manuscript.

\section{ORCID}

Ahlem Trifi

https://orcid.org/0000-0001-5088-2310

\section{AUTHOR CONTRIBUTIONS}

Conceptualization: AT, SA, AA. Data curation: YM, AM, OB, BJ, CA, FD. Formal analysis: AT, SA, AA, SBL. Methodology: AT, AM, OB, ES, FC. Project administration: AT, YM, AM. Visualization: AT, YM, YT, FD. Writing-original draft: AT, YM, YT, BJ, CA. Writing-review \& editing: SA, AA, SBL.

\section{REFERENCES}

1. White-Dzuro G, Gibson LE, Zazzeron L, White-Dzuro C, Sullivan Z, Diiorio DA, et al. Multisystem effects of COVID-19: a concise review for practitioners. Postgrad Med 2021;133:20-7.

2. Grasselli G, Zangrillo A, Zanella A, Antonelli M, Cabrini L,
Castelli A, et al. Baseline characteristics and outcomes of 1591 patients infected with SARS-CoV-2 admitted to ICUs of the Lombardy region, Italy. JAMA 2020;323:1574-81.

3. Guan WJ, Ni ZY, Hu Y, Liang WH, Ou CQ, He JX, et al. Clinical characteristics of coronavirus disease 2019 in China. N Engl J Med 2020;382:1708-20.

4. Richardson S, Hirsch JS, Narasimhan M, Crawford JM, McGinn T, Davidson KW, et al. Presenting characteristics, comorbidities, and outcomes among 5700 patients hospitalized with COVID-19 in the New York city area. JAMA 2020;323:2052-9.

5. Xie J, Wu W, Li S, Hu Y, Hu M, Li J, et al. Clinical characteristics and outcomes of critically ill patients with novel coronavirus infectious disease (COVID-19) in China: a retrospective multicenter study. Intensive Care Med 2020;46:1863-72.

6. Gheblawi M, Wang K, Viveiros A, Nguyen Q, Zhong JC, Turner AJ, et al. Angiotensin-converting enzyme 2: SARS-CoV-2 receptor and regulator of the renin-angiotensin system: celebrating the 20th anniversary of the discovery of ACE2. Circ Res 2020;126:1456-74.

7. Diao B, Wang C, Wang R, Feng Z, Zhang J, Yang H, et al. Human kidney is a target for novel severe acute respiratory syndrome coronavirus 2 infection. Nat Commun 2021;12:2506.

8. Arentz M, Yim E, Klaff L, Lokhandwala S, Riedo FX, Chong M, et al. Characteristics and outcomes of 21 critically ill patients with COVID-19 in Washington state. JAMA 2020;323:1612-4

9. Yang X, Yu Y, Xu J, Shu H, Xia J, Liu H, et al. Clinical course and outcomes of critically ill patients with SARS-CoV-2 pneumonia in Wuhan, China: a single-centered, retrospective, observational study. Lancet Respir Med 2020;8:475-81.

10. Sang L, Chen S, Zheng X, Guan W, Zhang Z, Liang W, et al. The incidence, risk factors and prognosis of acute kidney injury in severe and critically ill patients with COVID-19 in mainland China: a retrospective study. BMC Pulm Med 2020;20:290.

11. Cheng Y, Luo R, Wang K, Zhang M, Wang Z, Dong L, et al. Kidney disease is associated with in-hospital death of patients with COVID-19. Kidney Int 2020;97:829-38.

12. Singer M, Deutschman CS, Seymour CW, Shankar-Hari M, Annane D, Bauer M, et al. The Third International Consensus Definitions for Sepsis and Septic Shock (Sepsis-3). JAMA 2016;315:801-10

13. Palevsky PM, Liu KD, Brophy PD, Chawla LS, Parikh CR, Thakar CV, et al. KDOQI US commentary on the 2012 KDIGO clinical practice guideline for acute kidney injury. Am J Kidney Dis 2013;61:649-72

14. De Rosa S, Samoni S, Ronco C. Creatinine-based definitions: from baseline creatinine to serum creatinine adjustment in in- 
tensive care. Crit Care 2016;20:69.

15. Bouchard J. Estimating baseline serum creatinine for assessing acute kidney injury: not a one size fits all approach. Kidney Int Rep 2021;6:562-4.

16. Chawla LS, Bellomo R, Bihorac A, Goldstein SL, Siew ED, Bagshaw SM, et al. Acute kidney disease and renal recovery: consensus report of the Acute Disease Quality Initiative (ADQI) 16 Workgroup. Nat Rev Nephrol 2017;13:241-57.

17. Zhou F, Yu T, Du R, Fan G, Liu Y, Liu Z, et al. Clinical course and risk factors for mortality of adult inpatients with COVID-19 in Wuhan, China: a retrospective cohort study. Lancet 2020; 395:1054-62.

18. Panitchote A, Mehkri O, Hastings A, Hanane T, Demirjian S, Torbic $H$, et al. Factors associated with acute kidney injury in acute respiratory distress syndrome. Ann Intensive Care 2019;9:74.

19. Nin N, Lorente JA, Soto L, Ríos F, Hurtado J, Arancibia F, et al. Acute kidney injury in critically ill patients with 2009 influenza A (H1N1) viral pneumonia: an observational study. Intensive Care Med 2011;37:768-74.

20. Darmon M, Clec'h C, Adrie C, Argaud L, Allaouchiche B, Azoulay E, et al. Acute respiratory distress syndrome and risk of AKI among critically ill patients. Clin J Am Soc Nephrol 2014;9:1347-53.

21. Chueh TI, Zheng CM, Hou YC, Lu KC. Novel evidence of acute kidney injury in COVID-19. J Clin Med 2020;9:3547.

22. Jhaveri KD, Meir LR, Flores Chang BS, Parikh R, Wanchoo R, Barilla-LaBarca ML, et al. Thrombotic microangiopathy in a patient with COVID-19. Kidney Int 2020;98:509-12.

23. Fuhrman DY, Kane-Gill S, Goldstein SL, Priyanka P, Kellum JA. Acute kidney injury epidemiology, risk factors, and outcomes in critically ill patients $16-25$ years of age treated in an adult intensive care unit. Ann Intensive Care 2018;8:26.

24. Zarbock A, Gomez H, Kellum JA. Sepsis-induced acute kidney injury revisited: pathophysiology, prevention and future therapies. Curr Opin Crit Care 2014;20:588-95.

25. Monteil V, Kwon H, Prado P, Hagelkrüys A, Wimmer RA, Stahl $\mathrm{M}$, et al. Inhibition of SARS-CoV-2 infections in engineered human tissues using clinical-grade soluble human ACE2. Cell 2020;181:905-13.e7.

26. Palazzuoli A, Mancone M, De Ferrari GM, Forleo G, Secco GG, Ruocco GM, et al. Antecedent administration of angiotensin-converting enzyme inhibitors or angiotensin ii receptor antagonists and survival after hospitalization for COVID-19 syndrome. J Am Heart Assoc 2020;9:e017364.

27. Lombardi R, Nin N, Peñuelas O, Ferreiro A, Rios F, Marin MC, et al. Acute kidney injury in mechanically ventilated patients: the risk factor profile depends on the timing of AKI onset. Shock 2017;48:411-7.

28. Ranieri VM, Giunta F, Suter PM, Slutsky AS. Mechanical ventilation as a mediator of multisystem organ failure in acute respiratory distress syndrome. JAMA 2000;284:43-4.

29. Kuiper JW, Vaschetto R, Della Corte F, Plötz FB, Groeneveld AB. Bench-to-bedside review: Ventilation-induced renal injury through systemic mediator release--just theory or a causal relationship? Crit Care 2011;15:228. 